\title{
The Accumulation of Key Stroke Risk Factors and Its Association With the Characteristics of Subjects: A Population Based Cross Sectional Study
}

\author{
Peng Zhang ${ }^{1 \dagger}$, Hang Jin ${ }^{2 \dagger}$, Zhen-Ni Guo ${ }^{1}$, Hui-Jie Sun ${ }^{3}$, Fu-Liang Zhang ${ }^{2}$, Xin Sun ${ }^{2 \star}$ and \\ Yi Yang ${ }^{1,2 *}$ \\ ${ }^{1}$ Clinical Trial and Research Center for Stroke, Department of Neurology, The First Hospital of Jilin University, Changchun, \\ China, ${ }^{2}$ Department of Neurology, The First Hospital of Jilin University, Changchun, China, ${ }^{3}$ Cadre Ward, The First Hospital of \\ Jilin University, Changchun, China
}

\section{OPEN ACCESS}

Edited by:

Tracey Weiland,

The University of Melbourne, Australia

Reviewed by:

Konstantinos Tziomalos Aristotle University of Thessaloniki,

Greece

Leonardo Roever,

Federal University of Uberlandia,

Brazil

${ }^{*}$ Correspondence:

Xin Sun

xiaoxin_sx@126.com

Yi Yang

doctoryangyi@163.com

tThese authors have contributed equally to this work

Specialty section: This article was submitted to Neuroepidemiology, a section of the journal Frontiers in Neurology

Received: 20 September 2018 Accepted: 23 October 2018

Published: 12 November 2018

Citation:

Zhang P, Jin H, Guo Z-N, Sun H-J, Zhang F-L, Sun $X$ and Yang $Y$ (2018) The Accumulation of Key Stroke Risk Factors and Its Association With the Characteristics of Subjects: A

Population Based Cross Sectional Study. Front. Neurol. 9:949.

doi: 10.3389/fneur.2018.00949
Background: Evidence has shown that the greater the accumulation of risk factors for stroke, the greater the risk of stroke. Early intervention in the accumulation of risk factors for stroke can effectively reduce the incidence of stroke. The study aimed to investigate the distribution of the number of certain risk factors for stroke (hypertension, hyperlipidemia, overweight and obesity, and diabetes) and to explore the cause of the accumulation of certain stroke risk factors.

Methods: A total of 4,052 participants aged 40 years or older were selected by the multistage stratified cluster sampling method in Dehui City in Jilin province, China. Descriptive data analyses were conducted. Multiple regression analyses were used to explore the adjusted association between the accumulation of key stroke risk factors and subjects' lifestyle and demographic characteristics.

Results: Overall, $84.1 \%$ of the participants in this study had one or more of the four certain risk factors for stroke. The odds ratios (ORs) and 95\% confidence intervals (Cls) of having $\geq 1, \geq 2$, and $\geq 3$ key stroke risk factors were 1.627 (1.258, 2.103), 1.446 (1.209, $1.728)$, and $1.394(1.164,1.670)$, respectively, for males compared to females. Similarly, the ORs and $95 \%$ Cls of having $\geq 1, \geq 2$, and $\geq 3$ key stroke risk factors were 1.227 (1.009, 1.492), $1.256(1.096,1.442)$, and $1.450(1.262,1.667)$, respectively, for partially salty diets compared to normal diets. Compared to people who did not exercise regularly, the ORs and $95 \%$ Cls of having $\geq 1, \geq 2$, and $\geq 3$ key stroke risk factors were 0.693 (0.544, $0.883), 0.800(0.679,0.944)$, and $0.775(0.659,0.913)$, respectively, for people who regularly exercised. Compared to people who without a family history of cerebrovascular diseases, the ORs and 95\% Cls were 1.418 (1.162, 1.732), 1.327 (1.154, 1.525), and 1.209 (1.050, 1.393), for people who with it.

Conclusions: Male, partially salty diets, and family history of cerebrovascular diseases were risk factors for the accumulation of certain stroke risk factors while regular physical exercise was a protective factor.

Keywords: stroke, risk factors, life style, accumulation, prevention 


\section{INTRODUCTION}

Stroke is typically characterized as a neurological deficit attributed to an acute focal injury of the central nervous system by a vascular cause (1), and is the main cause of long-term adult disability and the second major cause of death in China $(2,3)$. Although patients received standardized stroke treatment, many suffered from residual disabilities or cognitive deficits. Therefore, early prevention is essential to reducing the burden of stroke.

Blood pressure, blood lipids, blood glucose, and BMI are indicators that can be objectively measured in cross-sectional studies. Therefore, recall bias and other possible information bias can be effectively avoided. Hypertension, overweight or obesity, diabetes, and hyperlipidemia are well-established major risk factors for stroke with high population attributable risk (3). At the same time, the prevalence of these four diseases is high in Jilin province (4). Therefore, hypertension, overweight or obesity, diabetes, and hyperlipidemia are considered to be the key risk factors for stroke in this study. Evidence has shown that the greater the accumulation of risk factors for stroke, the greater the risk of stroke (5). Accordingly, early intervention in the accumulation of risk factors for stroke can effectively reduce the incidence of stroke. At present, studies regarding the influence of demographic characteristics and lifestyle on the aggregation of stroke risk factors are relatively rare.

This population-based cross-sectional study was part of the Stroke Screening and Prevention Programme of the National Health and Family Planning Commission of China. The survey was conducted in 2016 and supervised by the National Center for Stroke Control and Prevention. In this study, we explored the distribution of the number of risk factors for stroke. Adjusted associations between the number of accumulated stroke risk factors and demographic characteristics and lifestyle were also examined in order to clarify the strength of association.

\section{MATERIALS AND METHODS}

\section{Study Design and Population}

This population-based cross-sectional study was conducted among residents aged 40 years or older and were living in Dehui City for over 6 months in 2016. The multistage stratified

TABLE 1 | The prevalence rate of stroke risk factors in different age groups.

\begin{tabular}{|c|c|c|c|c|c|c|c|}
\hline Risk factors & $40 \sim$ & $50 \sim$ & $60 \sim$ & $70 \sim$ & Total & $F / \chi^{2}$ & $p$ \\
\hline Hypertension & & & & & & 189.065 & $<0.001$ \\
\hline Yes & $611(44.4)$ & $806(58.7)$ & 698(69.2) & $220(74.6)$ & 2335(57.6) & & \\
\hline No & $765(55.6)$ & $566(41.3)$ & $311(30.8)$ & $75(25.4)$ & $1717(42.4)$ & & \\
\hline Hyperlipidemia & & & & & & 50.788 & $<0.001$ \\
\hline Yes & $771(56.0)$ & $910(66.3)$ & 694(68.8) & 195(66.1) & 2570(63.4) & & \\
\hline No & $605(44.0)$ & 462(33.7) & 315(31.2) & 100(33.9) & 1482(36.6) & & \\
\hline Diabetes & & & & & & 46.527 & $<0.001$ \\
\hline Yes & $77(5.6)$ & 150(10.9) & $128(12.7)$ & 43(14.6) & 398(9.8) & & \\
\hline No & 1299(94.4) & 1222(89.1) & $881(87.3)$ & $252(85.4)$ & 3654(90.2) & & \\
\hline Overweight or obesity & & & & & & 22.110 & $<0.001$ \\
\hline Yes & $718(52.2)$ & $765(55.8)$ & $555(55.0)$ & $122(41.4)$ & 2160(53.3) & & \\
\hline No & $658(47.8)$ & $607(44.2)$ & $454(45.0)$ & $173(58.6)$ & 1892(46.7) & & \\
\hline BMI & $24.47 \pm .3 .35$ & $24.61 \pm 3.32$ & $24.44 \pm 3.35$ & $23.53 \pm 3.30$ & $24.47 \pm 3.35$ & 8.844 & $<0.001$ \\
\hline Waist circumference & $83.27 \pm 9.33$ & $86.03 \pm 8.89$ & $87.97 \pm 9.11$ & $86.31 \pm 8.61$ & 85.605 .9 .25 & 54.733 & $<0.001$ \\
\hline Regular exercise & & & & & & 68.424 & $<0.001$ \\
\hline Yes & 1072(77.9) & $1133(17.4)$ & $765(75.8)$ & $180(61.0)$ & $3150(77.7)$ & & \\
\hline No & $304(22.1)$ & 239(82.6) & $244(24.2)$ & 115(39.0) & 902(22.3) & & \\
\hline Smoking & & & & & & 37.792 & $<0.001$ \\
\hline Yes & $384(27.9)$ & 508(37.0) & $381(37.8)$ & 100(33.9) & 1373(33.9) & & \\
\hline No & $754(54.8)$ & $641(46.7)$ & $474(47.0)$ & 156(52.9) & 2025(50.0) & & \\
\hline Passive & 238(17.3) & 223(16.3) & 154(15.2) & 39(13.2) & $654(16.1)$ & & \\
\hline Drinking & & & & & & 16.229 & 0.001 \\
\hline Yes & 403(29.3) & $370(27.0)$ & $244(24.2)$ & 57(19.3) & 1094(26.5) & & \\
\hline No & 973(70.7) & 1002(73.0) & $765(75.8)$ & 238(80.7) & 2978(73.5) & & \\
\hline Family history of cerebrovascular diseases & & & & & & 13.590 & 0.004 \\
\hline Yes & $504(36.6)$ & $474(34.5)$ & $344(34.1)$ & $75(25.4)$ & 2655(65.5) & & \\
\hline No & $872(63.4)$ & $898(65.5)$ & $665(65.9)$ & $220(74.6)$ & 1397(34.5) & & \\
\hline Family history of coronary artery disease & & & & & & 14.672 & 0.002 \\
\hline Yes & $379(27.5)$ & $352(25.7)$ & 223(22.1) & $57(19.3)$ & $1011(25.0)$ & & \\
\hline No & $997(72.5)$ & $1020(74.3)$ & $786(77.9)$ & 238(80.7) & $3041(75.0)$ & & \\
\hline
\end{tabular}




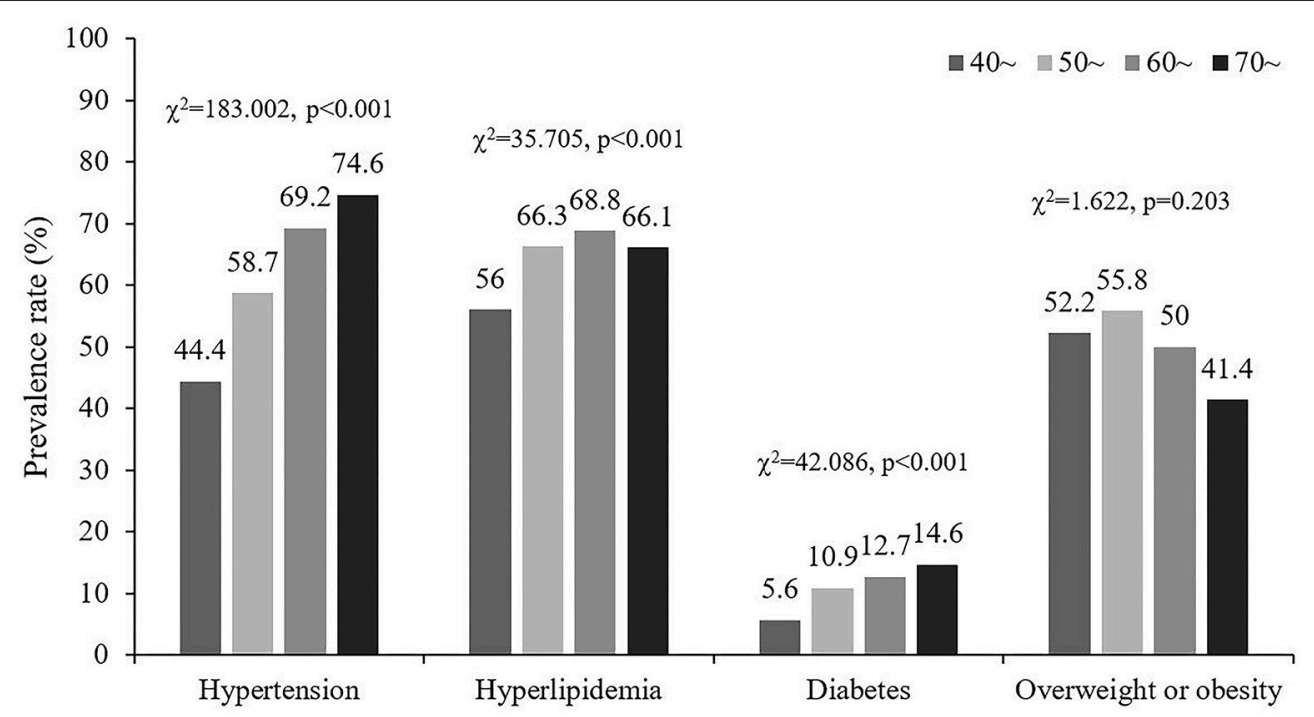

Note: Linear-by-Linear association

FIGURE 1 | The prevalence rate of stroke risk factors in different age groups.

cluster sampling method was used to select the study sample in Dehui City in Jilin province, China. In the first stage, the districts of Dehui city were divided into rural and urban area. In the second stage, 30 villages (rural) and 10 towns (urban) were randomly selected using probability proportional to size (PPS) sampling. In the third stage, 4 or 5 communities were sampled from both urban and rural area using PPS. Finally, 1 adult resident was randomly selected from each household of the selected communities (6). A total of 4,445 subjects were recruited and 4,100 completed the survey, a response rate of $92.23 \%$. After excluding the subjects without complete information of values, 4,052 subjects were included in this study.

\section{Ethical Standards}

This study was approved by the human ethics and research ethics committee of the First Hospital of Jilin University (approval No: 2015-R-250), and written informed consent was obtained from all the participants.

\section{Data Collection}

All data were collected by an interviewer administered questionnaire. The questionnaire was composed of three parts: general information (socio-demographic characteristics and health-related information), body measurements (such as height, weight, and blood pressure), and laboratory results (such as blood lipids). The investigators had been uniformly trained and followed the same questionnaire instruction. Eligible investigators had to pass an examination at the end of training.

\section{Measurements}

The subjects' heights and weights were measured without shoes and wearing light clothing according to a standardized protocol and technique. The accuracy of the measurement were $0.1 \mathrm{~cm}$ and $0.1 \mathrm{~kg}$, respectively. Blood pressure was measured using an electronic sphygmomanometer (OMRON HEM-7200). Each participant rested for at least $20 \mathrm{~min}$ before measurements were taken, and the average value of two measurements was adopted. The blood samples were obtained in the morning from subjects after fasting for at least $8 \mathrm{~h}$ and transported to a clinical laboratory (Changchun Kingmed Centre for Clinical Laboratory Co. Ltd.). The blood samples were examined within $8 \mathrm{~h}$ to measure fasting blood glucose (FBG), total cholesterol (TC), triglyceride (TG), low-density lipoprotein cholesterol (LDL-C), and high-density lipoprotein cholesterol (HDL-C).

\section{Definitions}

The diagnosis of hyperlipidemia was based on the criteria of the "Chinese Guidelines on Prevention and Treatment of Dyslipidemia in Adults": $\mathrm{TC} \geq 5.18 \mathrm{mmol} / \mathrm{L}$ or $\mathrm{TG} \geq 1.70$ $\mathrm{mmol} / \mathrm{L}$ or HDL-C $<1.04 \mathrm{mmol} / \mathrm{L}$ or $\mathrm{LDL}-\mathrm{C} \geq 3.37 \mathrm{mmol} / \mathrm{L}$ or previous diagnosis of hyperlipidemia by a physician (7). Those previously diagnosed by a physician or those with a fasting plasma glucose $(\mathrm{FPG})$ of $\geq 7.0 \mathrm{mmol} / \mathrm{L}$ were defined as diabetic (8). Systolic $\geq 140 \mathrm{mmHg}$ or diastolic $\geq 90 \mathrm{mmHg}$ and/or self-reported hypertension were regarded as hypertension (9). According to the criteria of weight for Chinese adults, $24 \leq \mathrm{BMI}$ $<28$ were defined as overweight, and $28 \leq$ BMI were defined as obesity (10). Smoking was defined as having smoked one or more cigarettes every day for more than 6 months. Those who had never smoked were defined as non-smokers. Those who have been smoking for $<6$ months were also defined as nonsmokers. Those who had never smoked but having been passively exposed to tobacco smoke were defined as passive smokers (11). Drinking was defined as consuming more than 3 alcoholic drinks per day or 7 drinks per week according to the National Institute on Alcohol Abuse and Alcoholism (NIAAA) guidelines (that 
TABLE 2 | The relationship between the participants' characteristics and the number of certain stroke risk factors, $n$ (\%).

\begin{tabular}{|c|c|c|c|c|c|c|c|}
\hline Characteristics & 0 & 1 & 2 & 3 & 4 & Cramer's V or Gamma & $p$ \\
\hline Total & $565(13.9)$ & $975(24.1)$ & $1211(29.9)$ & 1095(27.0) & 206(5.1) & & \\
\hline Sex & & & & & & 0.094 & $<0.001$ \\
\hline Male & $175(10.8)$ & $367(22.7)$ & 495(30.6) & 499(30.8) & $83(5.1)$ & & \\
\hline Female & 390(16.0) & $608(25.0)$ & $716(29.4)$ & $596(24.5)$ & $123(5.1)$ & & \\
\hline Area & & & & & & 0.052 & 0.028 \\
\hline Urban & $304(14.7)$ & $455(22.0)$ & $634(30.7)$ & $572(27.7)$ & 102(4.9) & & \\
\hline Rural & $261(13.1)$ & $520(26.2)$ & $577(29.1)$ & $523(26.4)$ & $104(5.2)$ & & \\
\hline Age (year) & & & & & & 0.185 & $<0.001$ \\
\hline $40 \sim$ & $302(21.9)$ & 362(26.3) & 352(25.6) & 323(23.5) & $37(2.7)$ & & \\
\hline $50 \sim$ & $147(10.7)$ & $342(24.9)$ & 424(30.9) & $383(27.9)$ & $76(5.6)$ & & \\
\hline $60 \sim$ & $94(9.3)$ & 200(19.8) & 326(32.3) & $313(31.1)$ & $76(7.5)$ & & \\
\hline $70 \sim$ & $22(7.5)$ & $71(24.1)$ & 109(36.9) & $76(25.7)$ & $17(5.8)$ & & \\
\hline Education & & & & & & -0.065 & $<0.001$ \\
\hline Primary school and below & 158(10.9) & $363(25.1)$ & $436(30.2)$ & 409(28.3) & $80(5.5)$ & & \\
\hline Junior middle school & 252(14.9) & $390(23.0)$ & $514(30.3)$ & $452(26.6)$ & $88(5.2)$ & & \\
\hline Senior middle school & $91(16.9)$ & $121(22.5)$ & 156(29.1) & $142(26.4)$ & $27(5.1)$ & & \\
\hline College and above & $64(17.2)$ & $101(27.1)$ & 105(28.2) & $92(24.6)$ & $11(2.9)$ & & \\
\hline Smoking & & & & & & 0.026 & 0.701 \\
\hline Yes & 183(13.3) & $350(25.5)$ & 399(29.1) & $368(26.8)$ & $73(5.3)$ & & \\
\hline No & 299(14.8) & $471(23.3)$ & $610(30.1)$ & $549(27.1)$ & $96(4.7)$ & & \\
\hline Passive & $83(12.7)$ & 154(23.5) & 202(30.9) & 178(27.2) & $37(5.6)$ & & \\
\hline Drinking & & & & & & 0.071 & $<0.001$ \\
\hline Yes & $118(11.0)$ & 236(22.0) & 335(31.2) & $331(30.8)$ & $54(5.0)$ & & \\
\hline No & $447(15.0)$ & $739(24.8)$ & $876(29.4)$ & $764(25.7)$ & 152(5.1) & & \\
\hline Partially salty diet & & & & & & 0.087 & $<0.001$ \\
\hline Yes & $191(12.2)$ & 359(22.9) & $439(28.0)$ & $497(31.7)$ & $81(5.2)$ & & \\
\hline No & $374(15.1)$ & $616(24.7)$ & $772(31.1)$ & $598(24.1)$ & $125(5.0)$ & & \\
\hline Regular exercise & & & & & & 0.066 & 0.001 \\
\hline Yes & $465(14.8)$ & $772(24.5)$ & 939(29.8) & $830(26.3)$ & $144(4.6)$ & & \\
\hline No & $100(11.1)$ & 203(22.5) & 272(30.1) & 265(29.4) & $62(6.9)$ & & \\
\hline Family history of cerebrovascular diseases & & & & & & 0.057 & 0.010 \\
\hline Yes & 166(11.9) & $315(22.5)$ & $435(31.2)$ & 403(28.8) & $78(5.6)$ & & \\
\hline No & 399(15.0) & $660(24.9)$ & $776(29.2)$ & $692(26.1)$ & $128(4.8)$ & & \\
\hline Dietary pattern & & & & & & 0.039 & 0.147 \\
\hline Balanced & $336(14.2)$ & $563(23.9)$ & 692(29.3) & $657(27.9)$ & $111(4.7)$ & & \\
\hline More meats & $31(11.7)$ & $52(19.7)$ & 80(30.3) & $84(31.9)$ & $17(6.4)$ & & \\
\hline More vegetables & 198(13.9) & $360(25.2)$ & 439(30.6) & $354(24.8)$ & $78(5.5)$ & & \\
\hline Fruit consumption (times per week) & & & & & & -0.025 & 0.481 \\
\hline$\leq 2$ & 15(13.3) & $28(24.8)$ & $31(27.4)$ & $35(31.0)$ & $4(3.5)$ & & \\
\hline $3-4$ & 49(13.6) & $77(21.4)$ & $114(31.9)$ & 105(29.2) & 14(3.9) & & \\
\hline$\geq 5$ & $501(14.0)$ & $870(24.3)$ & 1066(29.7) & $955(26.7)$ & $188(5.3)$ & & \\
\hline
\end{tabular}

is, any drink containing $14 \mathrm{~g}$ of pure alcohol) (12). Irregular exercise was defined as physical exercise $<3$ times a week for $<$ 30 min each session, and this included industrial and agricultural labor. A balance diet and salty diet were defined according to "Dietary guidelines for Chinese Residents (2007)" (13). Direct relatives in the three generation suffered from cerebrovascular diseases (Cerebral atherosclerosis, thrombosis, and stroke etc.) were defined as having a family history of cerebrovascular disease.

\section{Statistical Analysis}

Descriptive data analyses were conducted. Frequency distribution was used to present the subjects' characteristics, and the prevalence of stroke risk factors were reported using percentages. The chi-squared test was used to compare the prevalence of stroke risk factors in different age groups. The result of the trend test was analyzed using linear-by-linear association. Cramer's V or Gamma was used to indicate the relationship between the participants' characteristics and the 

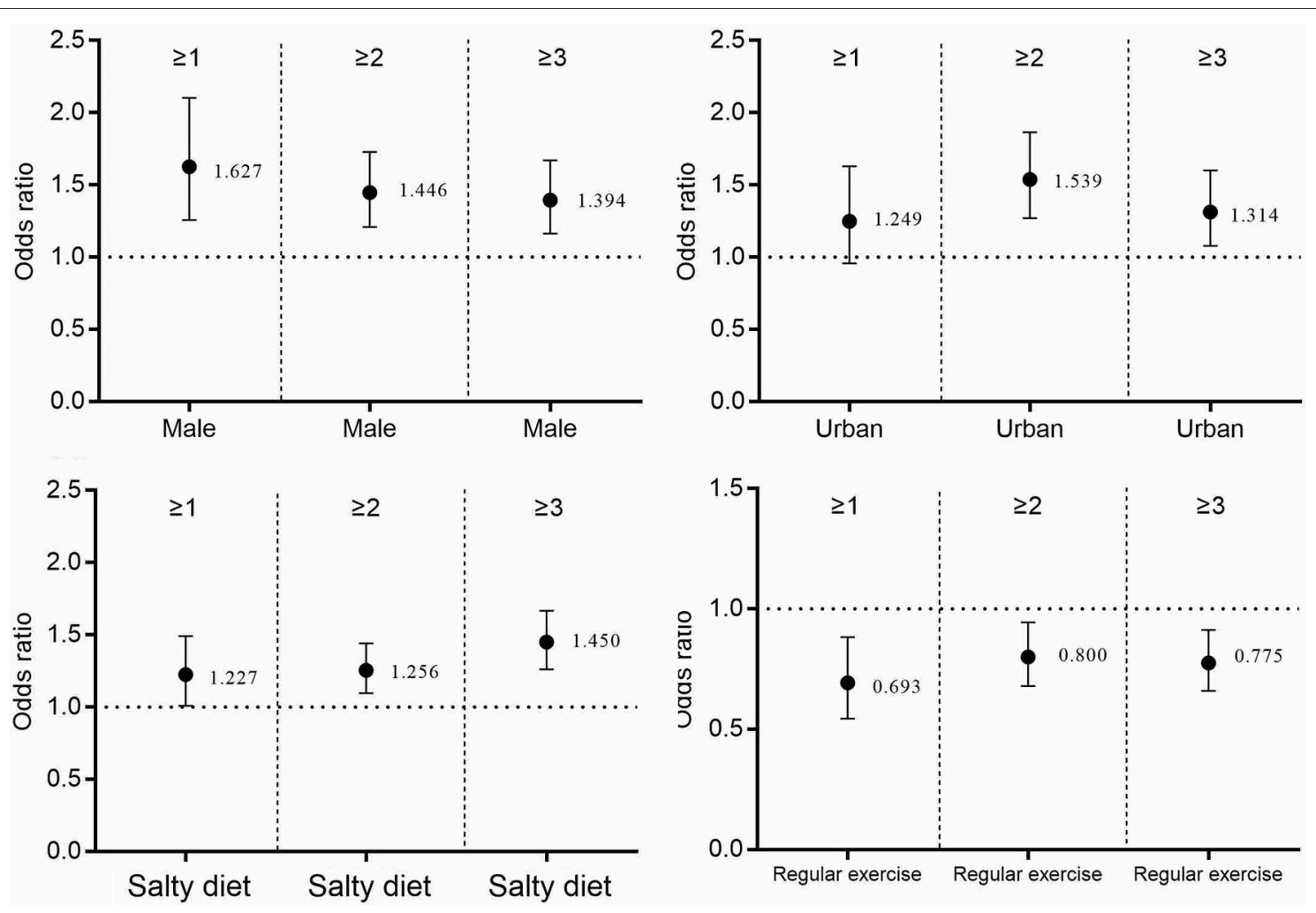

FIGURE 2 | The accumulation of stroke risk factors and their association with sex, area, salty diet, and exercise.

number of key stroke risk factors. Multiple regression analyses were used to explore the adjusted association between the participants' characteristics and the number of key stroke risk factors. All tests were two-tailed, and $P<0.05$ was considered statistically significant. Data analyses were conducted using SPSS 22.0 (IBM Corp., Armonk, NY, USA).

\section{RESULTS}

A total of 4,052 participants aged 40 years or older were eventually included in this study. The mean age of the participants was $54.85 \pm 9.30,40.0 \%$ were male, and $51.0 \%$ were urban residents. Supplementary Table I showed that the majority were between 40 and 49 years old and had a junior middle-school education. The smoking rate was $33.9 \%$ and the drinking rate was $26.5 \%$. Overall, $77.7 \%$ of the participants exercised regularly, $38.7 \%$ preferred salty diets, and $34.5 \%$ had family history of cerebrovascular diseases. Most of the participants had a balanced diet (58.2\%) and ate fruit $\geq 5$ times per week $(88.3 \%)$.

The prevalence of hypertension and diabetes were the highest in the 70 year-old group, while hyperlipidemia was highest in the 60- to 69-year-old group (Table 1). The lowest prevalence of hypertension, hyperlipidemia, and diabetes were in 40 - to 49-year-old group. Figure 1 showed that the prevalence of hypertension, hyperlipidemia and diabetes had a tendency to increase with age. The chi-squared trends were 183.002, 35.705, and 42.086 , respectively, and the $p$-values were all $<0.001$.
Table 2 describes the relationship between the participants' characteristics and the number of key stroke risk factors. $24.1 \%$ of the participants in this study had one of the four risk factors for stroke; $29.9 \%$ had two of the four risk factors for stroke; $27.0 \%$ had three of the four risk factors for stroke; $5.1 \%$ had four risk factors for stroke. Overall, $84.1 \%$ of the participants in this study had one or more of the four certain risk factors for stroke. It also showed that the number of key stroke risk factors for the participants were related to sex, area, age, education, drinking alcohol, partially salty diet, regular exercise, and family history of cerebrovascular diseases. The number of key stroke risk factors were increased with age and decreased with education.

Figures 2-4 and Table 3 describes the accumulating of key stroke risk factors and the association with the participants' characteristics. The odds ratios (OR) and 95\% confidence intervals (CIs) of having $\geq 1, \geq 2$, and $\geq 3$ key stroke risk factors were 1.627 (1.258, 2.103), 1.446 (1.209, 1.728), and 1.394 (1.164, 1.670), respectively, for males compared to females. Similarly, the ORs and $95 \%$ CIs of having $\geq 1, \geq 2$, and $\geq 3$ key stroke risk factors were $1.227(1.009,1.492), 1.256(1.096,1.442)$, and 1.450 $(1.262,1.667)$, respectively, for partially salty diets compared to normal diets. Compared to people who did not exercise regularly, the ORs and $95 \%$ CIs of $\geq 1, \geq 2$, and $\geq 3$ key stroke risk factors were $0.693(0.544,0.883), 0.800(0.679,0.944)$ and $0.775(0.659$, $0.913)$, respectively, for those who exercised regularly. When family history of cerebrovascular diseases was the risk factor, and the ORs and 95\% CIs were 1.418 (1.162, 1.732), 1.327 (1.154, $1.525)$, and $1.209(1.050,1.393)$. Data showed that the ORs and 

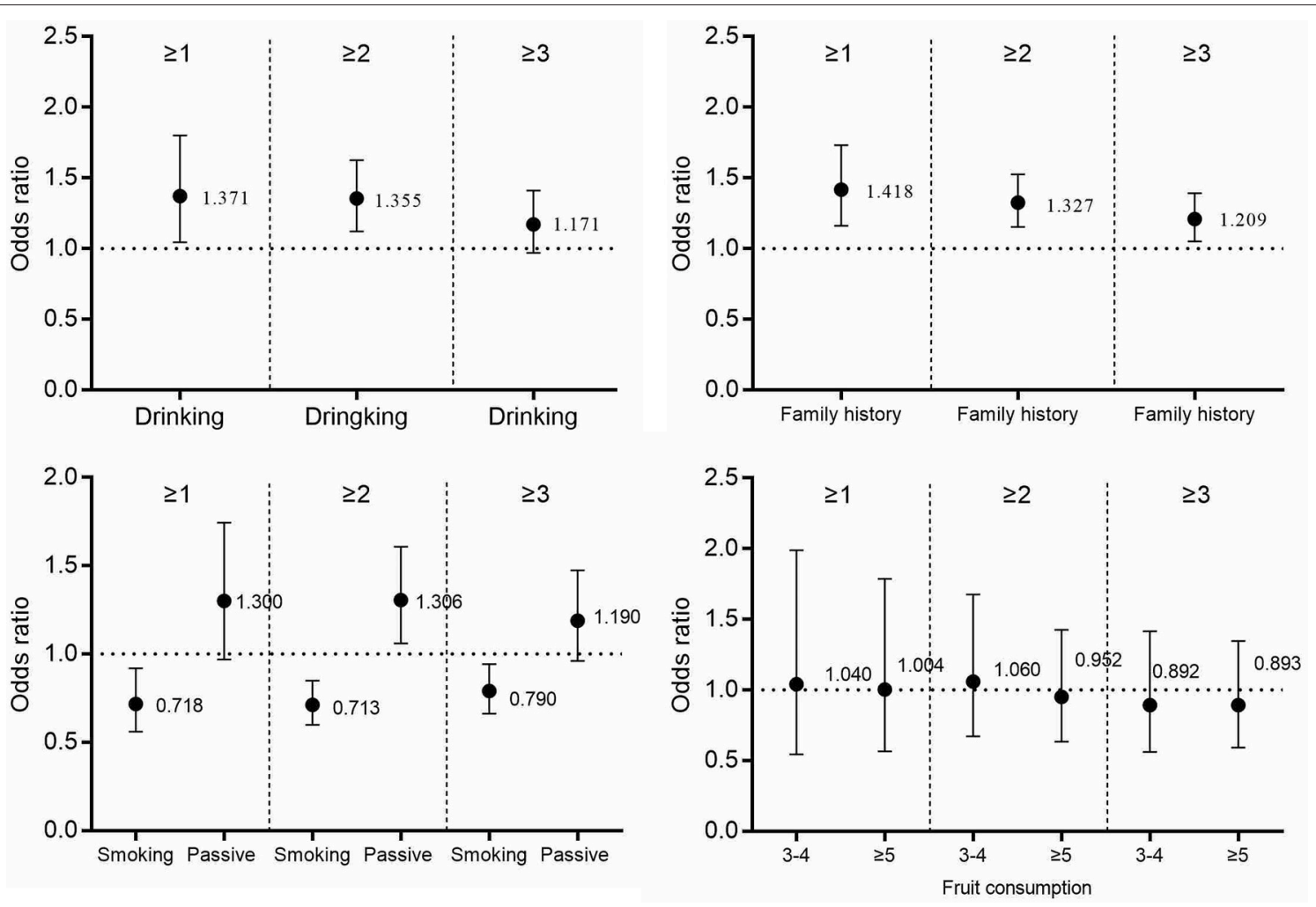

FIGURE 3 | The accumulation of stroke risk factors and their association with drinking, smoking, fruit consumption, and family history of cerebrovascular diseases.

95\% CIs of having $\geq 1, \geq 2$, and $\geq 3$ key stroke risk factors were $0.718(0.561,0.919), 0.713(0.600,0.849)$, and $0.790(0.662,0.943)$, respectively, for smokers compared to non-smokers.

\section{DISCUSSION}

This population-based cross-sectional study was the first investigation of stroke and its risk factors in Dehui City in Jilin province, China. As the prevalence and incidence of stroke were significantly increased after 39 years of age, the included participants were over 39 (14). Compared to another populationbased cross-sectional survey conducted in Jilin province among residents who were 18-79 years old in 2012, the prevalence of hypertension, hyperlipidemia, and being overweight or obese in this study were higher (57.6 vs. $36.9 \%$; 63.4 vs. $56.81 \%$; 53.3 vs. $46.9 \%$, respectively), while the prevalence of diabetes was lower $(9.8$ vs. $10.1 \%)(4,15)$. Due to the different age of the two survey, we could not draw a conclusion that the prevalence of hypertension, hyperlipidemia, and being overweight or obese in Dehui City were higher than other places in Jilin province, but we could conclude that the prevalence of diabetes in Dehui City was lower than other areas in Jilin province, as the prevalence of diabetes among people younger than 39 years old was lower than that of people over 39 (16).

The results showed that the prevalence of hypertension, hyperlipidemia, and diabetes had a tendency to increase with age. Studies indicated that advanced age was a risk factor for hypertension, hyperlipidemia, and diabetes, consistent with our findings (16-18). High blood pressure in elderly people could be explained by increased arterial stiffness, which typically accompanies aging and might be exacerbated by high blood pressure (19). Diabetes in the elderly was related to alterations in body composition and to reduced physical activity (20). In this study, the prevalence of overweight or obesity increased first and then decreased with age, and the highest was at 50 to 59 years of age. Ahmed's study reported similar results: 46- to 55-yearolds had the highest prevalence of overweight or obesity (21). It indicates that more attention should be paid to the problem of obesity or overweight in middle-aged people.

A total of $84.1 \%$ of the participants in this study had one or more of the four risk factors for stroke which implied that most people over 40 years of age in Dehui City were exposed to the risk of stroke. The risk of accumulating stroke risk factors for males was higher than females. The possible explanation was that the prevalence of overweight or obesity and hypertension were higher in male than in female in this district, but there was no difference in the prevalence of dyslipidemia and diabetes between different sexes $(15,22-24)$. Our study also indicated that a partially salty diet and lack of physical activity were risk factors for the accumulating of key stroke risk factors. Some scientific advisories recommended that the first line of treatment for hypertension should be lifestyle changes, including low sodium diet and enough physical exercise (25). A low sodium 

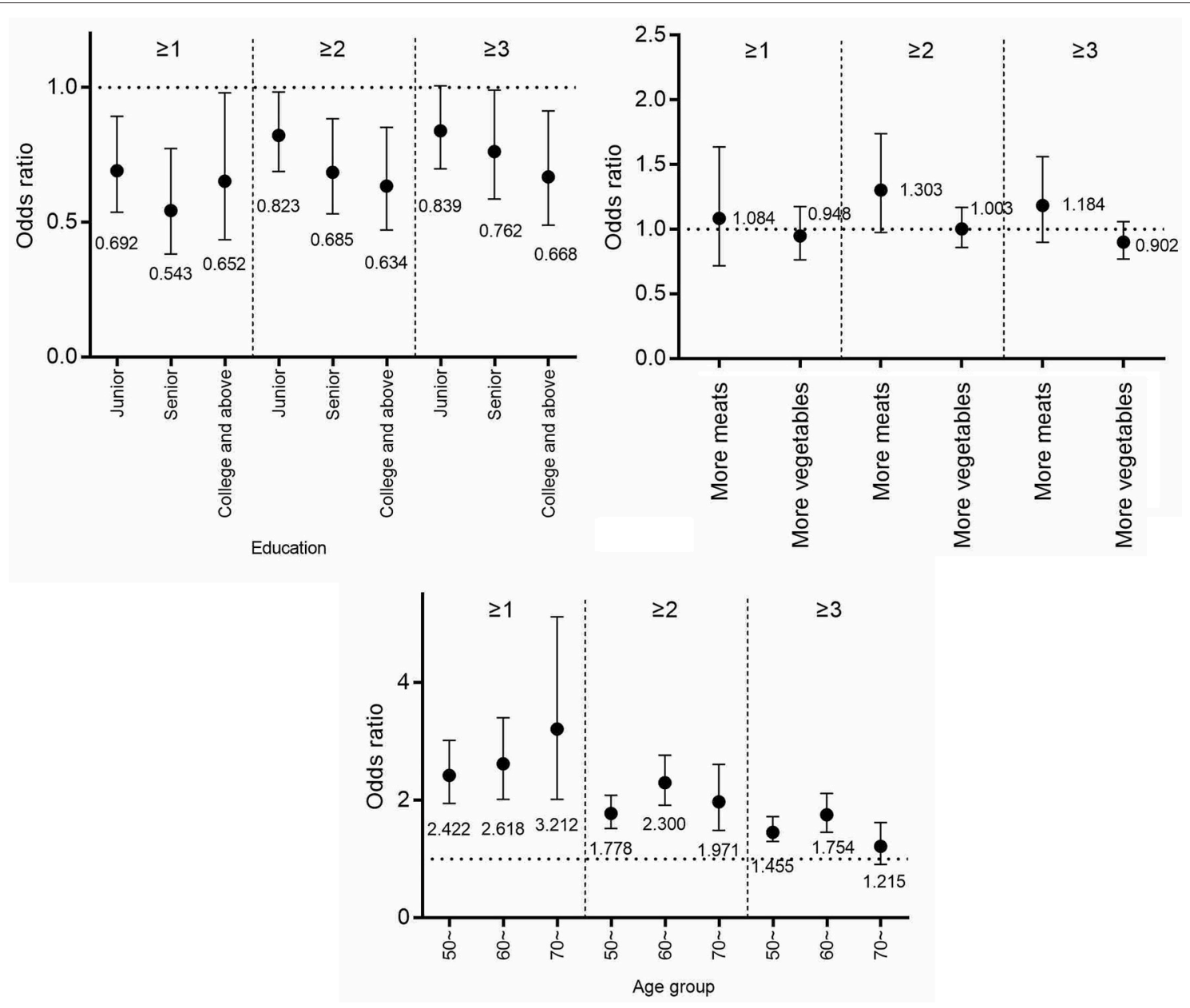

FIGURE 4 | The accumulation of stroke risk factors and their association with age, education, and diet patterns.

intake was associated with a reduced risk of cardiovascular disease and cerebrovascular disease in adults (26). Therefore, regular exercise and a low salt diet could reduce the risk of the accumulating of key stroke risk factors, thereby reducing the prevalence of stroke in Dehui City. Data showed that smoking was a protective factor for the accumulating of key stroke risk factors in our study. Although smoking was a risk factor for diabetes and hyperlipidemia $(27,28)$, Mehboudi's study indicated an inverse association between smoking and hypertension in an elderly population in Iran (29), and Wang's study indicated that smokers were less likely to be overweight or obese (15). These findings might explain why smoking was a protective factor for the accumulating of key stroke risk factors in our study. But smoking was an important risk factor for many kinds of diseases, so smoking was still a great threat to the health of residents.

\section{LIMITATIONS}

Our study has some potential limitations. Part of the results were based on self-reported data and the recall bias could not be avoided. In addition, the participants were recruited from Dehui
City of Jilin province, China, and the conclusion cannot represent the other places in Jilin province. Finally, those who were ill or too weak to complete the interview were not included in our survey.

\section{FUTURE DIRECTIONS}

Special attention should be paid to male or patients with family history of cerebrovascular disease in the primary prevention of stroke. Regular examination of blood pressure, blood fat, blood sugar, and BMI and effective control could reduce their risk of stroke. Health education should be carried out to encourage residents to take salt less diet and regular physical exercise in Dehui City. Although smoking is a protective factor for the accumulation of key stroke risk factors, it is also an important risk factor for many kinds of diseases. So smoking cessation is still crucial to the health of residents.

In conclusion, there was a high prevalence of certain key stroke risk factors among older adults in our study. Male, partially salty diets, and family history of cerebrovascular diseases were risk factors for the accumulating of certain stroke risk factors while regular physical exercise was a protective factor. 
TABLE 3 | The accumulation of certain stroke risk factors and the association with demographic characteristics and the subjects' lifestyles.

\begin{tabular}{|c|c|c|c|}
\hline \multirow[t]{2}{*}{ Factors } & \multicolumn{3}{|c|}{ OR(95\%Cl) } \\
\hline & $\geq 1$ & $\geq 2$ & $\geq 3$ \\
\hline \multicolumn{4}{|l|}{ GENDER } \\
\hline Male & $1.627(1.258,2.103)$ & $1.446(1.209,1.728)$ & $1.394(1.164,1.670)$ \\
\hline \multicolumn{4}{|l|}{ AREA } \\
\hline \multicolumn{4}{|l|}{ AGE $\left(\right.$ YEAR) ${ }^{\dagger}$} \\
\hline $40 \sim$ & 1 & 1 & 1 \\
\hline $50 \sim$ & $2.422(1.944,3.017)$ & $1.778(1.518,2.083)$ & $1.455(1.299,1.723)$ \\
\hline $60 \sim$ & $2.618(2.014,3.403)$ & $2.300(1.913,2.766)$ & $1.754(1.455,2.114)$ \\
\hline $70 \sim$ & $3.212(2.016,5.117)$ & $1.971(1.488,2.609)$ & $1.215(0.912,1.619)$ \\
\hline Senior middle school & $0.543(0.382,0.773)$ & $0.685(0.531,0.884)$ & $0.762(0.586,0.990)$ \\
\hline College and above & $0.652(0.435,0.980)$ & $0.634(0.472,0.852)$ & $0.668(0.489,0.913)$ \\
\hline \multicolumn{4}{|l|}{ SMOKING } \\
\hline No & 1 & 1 & 1 \\
\hline Yes & $0.718(0.561,0.919)$ & $0.713(0.600,0.849)$ & $0.790(0.662,0.943)$ \\
\hline Passive & $1.300(0.969,1.744)$ & $1.306(1.060,1.608)$ & $1.190(0.961,1.474)$ \\
\hline \multicolumn{4}{|l|}{ DRINKING } \\
\hline No & 1 & 1 & 1 \\
\hline Yes & $1.371(1.044,1.801)$ & $1.355(1.122,1.636)$ & $1.171(0.970,1.412)$ \\
\hline \multicolumn{4}{|l|}{ PARTIALLY SALTY DIET } \\
\hline No & 1 & 1 & 1 \\
\hline \multicolumn{4}{|l|}{ DIETARY PATTERN } \\
\hline Balanced & 1 & 1 & 1 \\
\hline More meats & $1.084(0.718,1.637)$ & $1.303(0.977,1.738)$ & $1.184(0.898,1.561)$ \\
\hline More vegetables & $0.948(0.764,1.176)$ & $1.003(0.860,1.170)$ & $0.902(0.769,1.059)$ \\
\hline \multicolumn{4}{|c|}{ FRUIT CONSUMPTION (TIMES PER WEEK) } \\
\hline$\leq 2$ & 1 & 1 & 1 \\
\hline $3-4$ & $1.040(0.544,1.989)$ & $1.060(0.671,1.675)$ & $0.892(0.562,1.415)$ \\
\hline$\geq 5$ & $1.004(0.565,1.786)$ & $0.952(0.635,1.426)$ & $0.893(0.592,1.346)$ \\
\hline
\end{tabular}

${ }^{\dagger}$ Trend test. $\geq 1(p<0.001) ; \geq 2(p<0.001) ; \geq 3(p<0.001)$.

$\neq$ Trend test. $\geq 1(p=0.014) ; \geq 2(p=0.001) ; \geq 3(p=0.008)$.

\section{AUTHOR CONTRIBUTIONS}

YY and Z-NG handled the conception and design. F-LZ, H-JS, and $\mathrm{XS}$ acquired the data. $\mathrm{PZ}$ performed the analysis. $\mathrm{PZ}$ and HJ drafted the manuscript. Z-NG and YY performed a critical revision.

\section{FUNDING}

This project was supported by the National Key R\&D Program of China (2016YFC1301600, 2016YFC1301603) to YY. This project was also supported by the Science and Technology Development Project of Jilin Province (20170520013JH) to HJ. 


\section{ACKNOWLEDGMENTS}

We would like to acknowledge all of the study participants and interviewers from the First Hospital of Jilin University. We gratefully acknowledge the support from the Chinese National Center for Stroke Care Quality Control and Management.

\section{REFERENCES}

1. Sacco RL, Kasner SE, Broderick JP, Caplan LR, Connors JJ, Culebras A, et al. An updated definition of stroke for the 21st century: a statement for healthcare professionals from the American Heart Association/American Stroke Association. Stroke (2013) 44:2064-89. doi: 10.1161/STR.0b013e318296aeca

2. Liu L, Wang D, Wong KS, Wang Y. Stroke and stroke care in China: huge burden, significant workload, and a national priority. Stroke (2011) 42:3651-4. doi: 10.1161/strokeaha.111.635755

3. Liu M, Wu B, Wang WZ, Lee LM, Zhang SH, Kong LZ. Stroke in China: epidemiology, prevention, and management strategies. Lancet Neurol. (2007) 6:456-64. doi: 10.1016/s1474-4422(07)70004-2

4. Zhang P, Wang R, Gao C, Song Y, Lv X, Jiang L, et al. Types of obesity and its association with the clustering of cardiovascular disease risk factors in Jilin province of China. Int J Environ Res Public Health (2016) 13:685. doi: 10.3390/ijerph13070685

5. Zhou Y, Tian Y, Zhong C, Batu B, Xu T, Li H, et al. Clustering of cardiovascular risk factors and stroke: a prospective cohort study in Inner Mongolia. Neurol Res. (2016) 12:1-6. doi: 10.1080/01616412.2016.1243610

6. Zhang FL, Guo ZN, Wu YH, Liu HY, Luo Y, Sun MS, et al. Prevalence of stroke and associated risk factors: a population based cross sectional study from northeast China. BMJ Open (2017) 7:e015758. doi: 10.1136/bmjopen-2016-015758

7. Joint committee for developing Chinese guidelines on prevention and treatment of dyslipidemia in adult. Chinese guidelines on prevention and treatment of dyslipidemia in adults. Chin J Cardiol. (2007) 35:390-419.

8. American Diabetes Association. Diagnosis and classification of diabetes mellitus. Diabetes Care (2008) 31:S55-60. doi: 10.2337/dc08-S055

9. Liu L. Guidelines for prevention and treatment of hypertension in China 2010. Chin J Hypertens. (2011) 8:701-43. doi: 10.16439/j.cnki.1673-7245.2011.08.009

10. Criterion of Weight for Adults. The National health and Family Planning Commision of the people's Repubic of China (2013).

11. Stroke Screening and Prevention Project Committee NHaFPCoC. Technical specification of stroke screening and prevention in China. Chinese J Front Med Sci. (2013) 9:44-50.

12. Willenbring ML, Massey SH, Gardner MB. Helping patients who drink too much: an evidence-based guide for primary care clinicians. Am Fam Physician (2009) 80:44-50. Available online at: https://www.aafp.org/afp/2009/0701/ p44.html

13. Chinese Nutrition Society. The Dietary Guidelines for Chinese Residents. Tibet, China: Tibetan People's Publishing House (2007).

14. Feigin VL, Krishnamurthi RV, Parmar P, Norrving B, Mensah GA, Bennett DA, et al. Update on the Global Burden of Ischemic and Hemorrhagic Stroke in 1990-2013: The GBD 2013 Study. Neuroepidemiology (2015) 45:161-76. doi: $10.1159 / 000441085$

15. Wang R, Zhang P, Gao C, Li Z, Lv X, Song Y, et al. Prevalence of overweight and obesity and some associated factors among adult residents of northeast China: a cross-sectional study. BMJ Open (2016) 6:e010828. doi: 10.1136/bmjopen-2015-010828

16. Bahendeka S, Wesonga R, Mutungi G, Muwonge J, Neema S, Guwatudde D. Prevalence and correlates of diabetes mellitus in Uganda: a populationbased national survey. Trop Med Int Health (2016) 21:405-16. doi: $10.1111 /$ tmi. 12663

17. Najafipour H, Shokoohi M, Yousefzadeh G, Sarvar Azimzadeh B, Moshtaghi Kashanian G, et al. Prevalence of dyslipidemia and its association with other coronary artery disease risk factors among urban population in Southeast of Iran: results of the Kerman coronary artery disease risk

\section{SUPPLEMENTARY MATERIAL}

The Supplementary Material for this article can be found online at: https://www.frontiersin.org/articles/10.3389/fneur. 2018.00949/full\#supplementary-material

factors study (KERCADRS). J Diabetes Metab Disord. (2016) 15:49. doi: 10.1186/s40200-016-0268-0

18. Kjeldsen SE. Hypertension and cardiovascular risk: general aspects. Pharmacol Res. (2017) 129:95-99. doi: 10.1016/j.phrs.2017.11.003

19. Zieman SJ, Melenovsky V, Kass DA. Mechanisms, pathophysiology, and therapy of arterial stiffness. Arterioscler Thromb Vasc Biol. (2005) 25:932-43. doi: 10.1161/01.atv.0000160548.78317.29

20. Sowers JR, Lester M. Hypertension, hormones, and aging. J Lab Clin Med. (2000) 135:379-86. doi: 10.1067/mlc.2000.106453

21. Ahmed MH, Ali YA, Awadalla H, Elmadhoun WM, Noor SK, Almobarak AO. Prevalence and trends of obesity among adult Sudanese individuals: Population based study. Diabetes Metab Syndr. (2017) 11(Suppl. 2):S963-7. doi: 10.1016/j.dsx.2017.07.023

22. Zhang FL, Xing YQ, Guo ZN, Wu YH, Liu HY, Yang Y. Prevalence and risk factors for diabetes and impaired fasting glucose in Northeast China: Results from the 2016 China National Stroke Screening Survey. Diabetes Res Clin Pract. (2018) 144:302-13. doi: 10.1016/j.diabres.2018.09.005

23. Wu J, Li T, Song X, Sun W, Zhang Y, Liu Y, et al. Prevalence and distribution of hypertension and related risk factors in Jilin Province, China 2015: a cross-sectional study. BMJ Open (2018) 8:e020126. doi: 10.1136/bmjopen-2017-020126

24. Zhang FL, Xing YQ, Wu YH, Liu HY, Luo Y, Sun MS, et al. The prevalence, awareness, treatment, and control of dyslipidemia in northeast China: a population-based cross-sectional survey. Lipids Health Dis. (2017) 16:61. doi: 10.1186/s12944-017-0453-2

25. Go AS, Bauman MA, Coleman King SM, Fonarow GC, Lawrence W, Williams KA, et al. An effective approach to high blood pressure control: a science advisory from the American Heart Association, the American College of Cardiology, and the Centers for Disease Control and Prevention. Hypertension (2014) 63:878-85. doi: 10.1161/hyp.00000000000 00003

26. Aburto NJ, Ziolkovska A, Hooper L, Elliott P, Cappuccio FP, Meerpohl JJ. Effect of lower sodium intake on health: systematic review and meta-analyses. Bmj (2013) 346:f1326. doi: 10.1136/bmj.f1326

27. Akter S, Goto A, Mizoue T. Smoking and the risk of type 2 diabetes in Japan: a systematic review and meta-analysis. J Epidemiol. (2017) 27:553-61. doi: 10.1016/j.je.2016.12.017

28. Ueyama C, Horibe H, Yamase Y, Fujimaki T, Oguri M, Kato K, et al. Association of smoking with prevalence of common diseases and metabolic abnormalities in community-dwelling Japanese individuals. Biomed Rep. (2017) 7:429-38. doi: 10.3892/br.2017.991

29. Mehboudi MB, Nabipour I, Vahdat K, Darabi H, Raeisi A, Mehrdad $\mathrm{N}$, et al. Inverse association between cigarette and water pipe smoking and hypertension in an elderly population in Iran: Bushehr elderly health programme. J Hum Hypertens. (2017) 31:821-5. doi: 10.1038/jhh. 2017.64

Conflict of Interest Statement: The authors declare that the research was conducted in the absence of any commercial or financial relationships that could be construed as a potential conflict of interest.

Copyright (C) 2018 Zhang, Jin, Guo, Sun, Zhang, Sun and Yang. This is an open-access article distributed under the terms of the Creative Commons Attribution License (CC $B Y)$. The use, distribution or reproduction in other forums is permitted, provided the original author(s) and the copyright owner(s) are credited and that the original publication in this journal is cited, in accordance with accepted academic practice. No use, distribution or reproduction is permitted which does not comply with these terms. 